\title{
TRAUMATIC EPILEPSY AFTER CLOSED HEAD INJURIES*
}

\author{
BY \\ W. BRYAN JENNETT and WALPOLE LEWIN
}

From the Accident Service and the Department of Neurological Surgery, the Radcliffe Infirmary, Oxford

It has long been known that epilepsy may follow injury to the head. The relationship between the two events has been worked out in some detail for missile wounds of the head by Wagstaffe (1928), Ascroft (1941), and Russell and Whitty (1952), to mention but a few of many such studies, the opportunities for which were provided by the two world wars. The well-defined injury made study precise, and, as the patients became pensioners, follow-up could be effective. The blunt head injuries of civilian life are less easy to study. The numbers involved, the diversity of injury, and the inevitable selection of cases for admission to hospital, pose major problems in obtaining an unselected series in which to study the true incidence of epilepsy and reliable standards to discuss the factors involved. We owe much, however, to the earlier work of Russell (1932), Feinberg (1934), Symonds (1935), Rowbotham (1942), Penfield and Shaver (1945), and Phillips (1954), who have published valuable reviews on this subject. Nevertheless, many of these studies have been on selected cases either due to the population studied, for example Service personnel, or because of the selection involved in admission to a special unit. As Garland (1942) pointed out in a discussion on traumatic epilepsy, the incidence claimed from various sources varied from $20 \%$ at its highest down to a figure less than that of epilepsy in the general population. Moreover, there seemed little agreement as to what constituted a mild or severe head injury.

Russell (1932) reported an incidence of epilepsy of $3.5 \%$ among 200 cases within 18 months of injury, Rowbotham (1942) $2.5 \%$ in 450 cases, and Phillips (1954) $6 \%$ in 500 cases. In this paper a further attempt has been made to estimate this complication of head injury, based it is believed, on an unselected series of cases. There are several unanswered questions in relation to traumatic epilepsy. What is the significance of epilepsy occurring in the acute

\footnotetext{
* A paper read to the International League Against Epilepsy in March, 1959.
}

period after injury ? Does it commonly indicate an intracranial complication, and is it associated with particular types of injury ? Can early epilepsy be ignored as far as the future is concerned or does it call for caution in prognosis ? This paper will be primarily concerned in answering these questions about early epilepsy, although some details will be given of the late follow-up (four to nine years) sufficient to give a general picture of the incidence of epilepsy. But a more detailed study of late epilepsy will be deferred to another occasion.

\section{MATERIAL AND INCIDENCE}

A thousand consecutive cases of head injury not caused by missiles admitted to the Accident Service at the Radcliffe Infirmary, Oxford, from November, 1948 , to February, 1952, have been studied. Of these, 46 patients had the first fit of their lives within a week of injury.

The great majority, 821, were admitted direct from the scene of the accident. As this was the only hospital in the area admitting accidents and all head injuries came to the Accident Service, this group represents, as far as is possible, an unselected series. The patients were under the care of a neurosurgeon from the outset, and this study was not a retrospective one, for one of the objects in compiling this series was to study epilepsy. Care was taken to record all possible details about fits, and to enquire about previous epilepsy and family history. There were only two patients with post-traumatic fits who had a family history of epilepsy. When there was doubt about the occurrence of a fit during the short period before admission ambulance drivers and others were questioned.

In such an unselected series as this (direct admission from the accident) there were many cases of mild injury, for a criterion for admission was evidence of cerebral concussion, as judged by a period of amnesia, even if brief. Thus approximately two-thirds of the surviving 750 direct admissions had less than an hour's post-traumatic amnesia, and 
there was a similar proportion without skull fracture. Of this unselected series of 821 cases, 31 developed epilepsy within one week of injury $(3.9 \%)$.

The remaining cases of the series (179) were patients transferred from other hospitals for special attention. Most had major head injuries and suspected complications; but not all, for some with less severe injuries were transferred from small peripheral hospitals, which were unable to provide continuing treatment. Nevertheless, this group did weigh the whole series in favour of more serious and complicated cases and is therefore mentioned separately in this paragraph. In this group there were 15 cases of early epilepsy $(8.4 \%)$.

A selecting factor, present in all series and in this one, was that some patients were transferred from other hospitals because of a fit after injury; and a few patients in the "direct" group were admitted after minor injury because of an early fit, particularly the infants, who will be referred to again. Sedatives were used sparingly in the general management of these cases, and anticonvulsants were not prescribed prophylactically for the uncomplicated cases during the acute period. Thus it is unlikely that many cases were suppressed by drug treatment.

\section{Previous Epilepsy}

In any large series of head injuries there are always some patients who have had previous fits or indeed have sustained their head injury during a fit. There were 14 such patients in this series and they have been excluded from the figures already mentioned. Most were subject to frequent fits and were known to be epileptics when admitted. However, two were discovered to have a history of epilepsy only when a full enquiry into their past was made consequent to their having a fit after the injury. In no case was the course of the patient's epilepsy altered significantly and only one of these 14 patients had a fit in the first week after injury. The ages and severity of injury of these patients showed a normal distribution similar to the rest of this series. Phillips (1954) also concluded that a personal history of epilepsy did not influence the onset of traumatic epilepsy. These cases are excluded from all subsequent analyses.

\section{Deaths}

There were 90 deaths among the 1,000 cases, and early epilepsy occurred in eight of them $(8.9 \%)$. With the exception of one patient who had a lucid interval before cerebral compression from an extradural haematoma, all were in coma from the time of injury until death. Of the eight cases, six had intracranial haematoma (q.v.).

\section{EARLY EPILEPSY}

As this series was analysed, it became possible to define the term "early epilepsy" much more precisely than seemed likely at the outset. It could be limited to the first week after injury, for only one patient in this series had his first fit between the seventh day and the eleventh week after injury. This patient made a good immediate recovery from a mild injury but developed a subdural haematoma which was evacuated two weeks after injury, and focal attacks developed post-operatively. This case has been included in the late group of epilepsy. Of the 46 patients who developed fits within a week of injury, a third had their first attack less than one hour after injury, a third within the first 24 hours, and a third from the second to seventh day.

This absence of cases with epilepsy first appearing between the first week and the third month compared with other series calls for an explanation. Possibly the opportunity afforded in this series of having many patients under continuous observation from soon after the time of injury enabled attacks in the first few hours after injury to be recorded which might have been missed in other circumstances. 0

Generalized attacks occurred in 18 patients and o focal attacks in 25 , of whom four also had grand 웅 mal. There were three patients with unusua范 attacks or with insufficient information to be quites sure whether a generalized attack had begun focally We have adopted the convention of Penfield anf Jasper (1954) in labelling as focal any attack which began unequivocally in a focal manner, in which is included adversion. In 20 of the 38 survivors the fits were repeated and in some of these serial epilepsy or status occurred.

\section{Factors Influencing Incidence of Early Epilepsy}

Age.-The incidence of fits in the group under 5 years of age was almost twice that in any other age group (Table I). Three of the seven infants with a fit had sustained only a trivial injury and indeed many of the children admitted had very mild injuries. This reflects the general policy governing the admission of young children after head injuries about

\section{TABLE I}

AGE GROUPS AND INCIDENCE OF EARLY EPILEPSY IN 896 SURVIVORS

\begin{tabular}{c|c|c|c}
\hline Age in Years & $\begin{array}{c}\text { Total No. of } \\
\text { Patients }\end{array}$ & $\begin{array}{c}\text { Early } \\
\text { Epilepsy }\end{array}$ & $\%$ Epilepsy \\
\hline Up to 5 & 75 & 7 & $9 \cdot 4$ \\
$6-15$ & 122 & 4 & $3 \cdot 3$ \\
$16-25$ & 257 & 13 & $5 \cdot 1$ \\
$26-45$ & 248 & 10 & $4 \cdot 1$ \\
$46-65$ & 132 & 2 & $1 \cdot 5$ \\
Over 65 & 62 & 2 & $3 \cdot 1$ \\
\hline
\end{tabular}


which accurate details are notoriously difficult to establish.

Several factors may contribute to this high incidence of fits in young children after trivial injuries. Considering the frequency with which infections precipitate fits at this age it seems that the brain is more susceptible. Moreover, children of this age are closely observed by their parents and are likely to be brought to hospital immediately if any incident such as a fit occurs, and three of our children were admitted because a fit had followed a trivial injury. Then some children may be predisposed to epilepsy by some underlying condition, either congenital or contracted during the perinatal period which, until the head injury, has not been brought to light. This was probably so in one of our patients. This was a child of 2 years and 9 months who proved to have a long-standing mild hemiplegia and had been a difficult breech delivery. That this child had only one further fit in the subsequent seven years suggests that the head injury must have been a major precipitating agent for the posttraumatic fit.

Another possibility is that the post-traumatic fit is the first one in a person destined to suffer from "idiopathic epilepsy". For the majority of such epileptics begin having convulsions in the first five years of life. The follow-up on this small group of children does not bear this out, for although all three with trivial injuries followed by an early fit did have another fit later on, none became a chronic epileptic. All were traced for seven years, and two had had only a single fit, and the other two episodes, during that time.

Severity of Injury.-The length of the posttraumatic amnesia is a useful guide to the degree of brain injury suffered, and we have used the time groupings originally suggested by Russell (1932). Table II shows that epilepsy was more than four times more common when the post-traumatic epilepsy was more than 24 hours. This, however, did not hold for the youngest age group which accounts for a number of cases without amnesia,

TABLE II

DURATION OF POST-TRAUMATIC AMNESIA AND RELATION TO EARLY EPILEPSY IN 896 SURVIVORS

\begin{tabular}{c|c|c|c}
\hline $\begin{array}{c}\text { Post-traumatic } \\
\text { Amnesia }\end{array}$ & $\begin{array}{c}\text { Total No. of } \\
\text { Patients }\end{array}$ & $\begin{array}{c}\text { Early } \\
\text { Epilepsy }\end{array}$ & $\%$ Epilepsy \\
\hline Nil & 108 & 7 & $6 \cdot 25$ \\
Less than 1 hour & 414 & 7 & $1 \cdot 7$ \\
1-24 hours & 207 & 6 & $2 \cdot 85$ \\
1-7 days & 64 & 7 & 11 \\
More than 7 days & 90 & 11 & 12 \\
No information & 13 & - & - \\
\hline
\end{tabular}

Less than 24 hours $20 / 729=2.7 \%$

More than 24 hours $18 / 154=12 \%$ and the special case of which has been discussed (vide supra). No patient over the age of 25 years developed epilepsy after an injury without amnesia and this held whether there was a fracture or not. This seems to indicate that the adult brain requires a more severe concussion to produce epilepsy than the child's. When patients with depressed fractures and with intracranial haematomas were excluded the incidence of epilepsy was more than five times greater in cases with more than 24 hours' posttraumatic amnesia.

As might be expected, the likelihood of early epilepsy was greater if abnormal signs were present on neurological examination, and most marked where motor or sensory hemisphere signs were present.

Fractured Skull.-Table III supports the widely held impression that epilepsy is commoner when a skull fracture is present. The association of epilepsy

TABLE III

SKULL FRACTURE WITH EARLY EPILEPSY IN 896 SURVIVORS

\begin{tabular}{l|c|c|c}
\hline Site of Fracture & $\begin{array}{c}\text { Total No. of } \\
\text { Patients }\end{array}$ & Epilepsy & \% Epilepsy \\
\cline { 2 - 4 } Frontal & 118 & 9 & $7 \cdot 6$ \\
Temporo-parietal & 172 & 15 & $8 \cdot 7$ \\
Occipital & 54 & 1 & $1 \cdot 3$ \\
No fracture & 552 & 13 & $2 \cdot 3$ \\
\hline
\end{tabular}

with fractures in sites other than occipital was 3.5 times commoner than in those cases without fracture, a relationship which held good whether the post-traumatic amnesia was more or less than 24 hours. From the comparatively small number of patients with fractures confined to the occipital bone it seems that epilepsy is very unusual after such injuries. Nor did any of the four patients with depressed fractures of the occipital bone develop epilepsy.

There were 64 patients with depressed fractures among the survivors in this series. Table IV shows that when considered in relation to fractures without depression early epilepsy is nearly twice as common

TABLE IV

INCIDENCE OF EARLY EPILEPSY WITH SURVIVING DEPRESSED FRACTURE

\begin{tabular}{|c|c|c|c|c|c|}
\hline \multirow{2}{*}{ Site of Fracture } & \multirow{2}{*}{$\begin{array}{c}\text { Total No. } \\
\text { of } \\
\text { Patients } \\
\text { with } \\
\text { Fractures }\end{array}$} & \multicolumn{2}{|c|}{$\begin{array}{c}\text { Depressed } \\
\text { Fracture }\end{array}$} & \multicolumn{2}{|r|}{$\begin{array}{c}\text { Linear } \\
\text { Fracture }\end{array}$} \\
\hline & & No. & $\begin{array}{l}\text { With } \\
\text { Epilepsy }\end{array}$ & No. & $\begin{array}{l}\text { With } \\
\text { Epilepsy }\end{array}$ \\
\hline $\begin{array}{l}\text { Frontal } \\
\text { Temporo-parietal } \\
\text { Occipital } \\
\text { All sites } \\
\text { All sites except } \\
\text { occipital }\end{array}$ & $\begin{array}{r}118 \\
172 \\
54 \\
344 \\
\\
290\end{array}$ & $\begin{array}{r}32 \\
28 \\
4 \\
64 \\
\\
60\end{array}$ & $\begin{array}{l}4(12.5 \%) \\
4(14.3 \%) \\
0 \quad(12.5 \%) \\
8(12.5 \%) \\
8(13.3 \%)\end{array}$ & $\begin{array}{r}86 \\
144 \\
50 \\
280 \\
230\end{array}$ & $\begin{aligned} 5 & (5.8 \%) \\
11 & (7.6 \%) \\
1 & (2 \%) \\
17 & (6.1 \%) \\
& (7.0 \%)\end{aligned}$ \\
\hline
\end{tabular}


when a fracture in the frontal, temporal, or parietal region is depressed, $13.3 \%$ compared with $7.0 \%$. This is so whether the post-traumatic amnesia is more or less than 24 hours.

The small numbers do not show any significant difference in the incidence of early epilepsy between those depressed fractures where the dura was penetrated and those where it was intact. This is not surprising so far as early epilepsy goes since most, if not all, of these cases have some degree of cerebral contusion beneath the fracture site, which is probably the cause of the early attacks. On the other hand, penetration of the dura, as will be shown when discussing late epilepsy, appears to increase considerably the likelihood of late epilepsy. One would expect this from experience with war wounds.

Intracranial Haemorrhage.-Spontaneous subarachnoid haemorrhage may be accompanied by epilepsy in the acute stage (Symonds, 1935; Walton, 1956). In the majority of cases of traumatic subarachnoid haemorrhage there is some degree of cortical contusion, although not in all, and it might therefore be expected that the finding of blood in the cerebrospinal fluid would be associated with a high incidence of epilepsy. In this series lumbar puncture was not a routine procedure but was usually performed where there was clinical evidence of subarachnoid haemorrhage. Of 174 patients so investigated, 124 had bloodstained cerebrospinal fluid and the incidence of epilepsy in these was $9.7 \%$, about twice that of the series as a whole. It should be noted that this was not merely an expression of the severity of the injury, for $43 \%$ of these 124 patients had a post-traumatic amnesia of less than 24 hours.

Intracranial haematomas (extradural, subdural, and intracerebral) are relatively uncommon in any series of unselected head injuries. In the 1,000 cases of this series there were 69 haematomas among 62 patients, an incidence of $6.2 \%$ (Lewin, 1953). There were 14 cases of early epilepsy among the 61 patients with haematoma $(22.9 \%)$. (One of these 62 patients with haematoma in the 1,000 cases is excluded on account of previous epilepsy.) Ten of these 14 patients had acute subdural or intracerebral clots, sometimes in association with an extradural haematoma. All the early fits associated with haematomas were focal, and presumably related to local cerebral damage rather than to remote effects.

It was unusual for a fit to be the sole sign of a developing haematoma, attacks occurring as a rule in patients already showing obvious signs of cerebral compression. However, a fit occurred during the evolution of three extradural haematomas among 16 which presented with a lucid interval. In two of these the fit was the first sign of deterioration, although other signs soon developed. In two other patients fits occurred in the post-operative phase, and in each a recurrent clot was proved to be forming. We conclude that an isolated fit with rapid recovery, and without other signs of cerebral compression, is very unlikely to be indicative of a developing intracranial clot, and would not of itself call for surgical exploration.

\section{LATE EPILEPSY}

Previous reviews have shown clearly that in the majority of cases the first fit is usually declared within two years of injury. In over $80 \%$ of the patients in the two most recent large series published of late epilepsy after head injury, the fits had occurred within this time. (Phillips, 1954; Gurdjian and Webster, 1958.)

The study of the present series was begun four years after the last case was admitted. This led to the difficulty of tracing patients four to nine years after injury, but meant that once traced each case was a valuable addition to knowledge about the late effects of injury. In the circumstances it was not possible to attempt to follow all 896 survivors. It was decided instead to follow some which would be representative of the series as a whole, and some from groups about whose future we were especially interested. Thus all who had suffered from early epilepsy were followed, as well as those withô depressed fractures, with haematomas, and with more than 24 hours post-traumatic amnesia. Too balance this the first 100 consecutive patients with? uncomplicated injuries and less than an hour's amnesia were traced. Only patients followed for more than four years after the injury are discussed in the following sections dealing with the late follow-up.

There were 275 patients followed, and 28 of them had one or more late fits (Table V). This number

TABLE V

RESULTS OF FOLLOW-UP FOR FOUR YEARS

\begin{tabular}{|c|c|c|c|c|}
\hline Clinical Groups & $\begin{array}{c}\text { Total } \\
\text { Survivors }\end{array}$ & $\begin{array}{l}\text { Satisfac- } \\
\text { tory } \\
\text { Follow- } \\
\text { up }\end{array}$ & $\begin{array}{c}\text { Late } \\
\text { Epilepsy }\end{array}$ & $\begin{array}{c}\% \text { of } \\
\text { Followed } \\
\text { Cases with } \\
\text { Late Epilepsy }\end{array}$ \\
\hline $\begin{array}{l}\text { Without Early Epilepsy } \\
\text { Depressed fracture }\end{array}$ & 56 & 44 & 7 & 16 \\
\hline $\begin{array}{l}\text { Post-traumatic am- } \\
\text { nesia }<\text { hour } \\
\text { (uncomplicated) }\end{array}$ & 100 & 100 & 1 & 1 \\
\hline $\begin{array}{l}\text { Post-traumatic am- } \\
\text { nesia }>24 \text { hours } \\
\text { or haematoma (but } \\
\text { without depressed } \\
\text { fracture) }\end{array}$ & 137 & 96 & 10 & $10 \cdot 4$ \\
\hline $\begin{array}{l}\text { Total without early } \\
\text { epilepsy }\end{array}$ & 293 & 240 & 18 & $7 \cdot 5$ \\
\hline After early epilepsy & 38 & 35 & 10 & $28 \cdot 5$ \\
\hline
\end{tabular}


of late epilepsies does not allow any detailed analysis of the various factors operating, but it is hoped to make such a study later when other cases outside the present series will be included. However, some valid comment can be made on the groups followed because of the high proportion of cases successfully traced. It is likely that the incidence of late fits may have been lower in this series than in the country as a whole, because it was our practice to prescribe prophylactic phenobarbitone for patients whom we deemed likely to develop epilepsy, as it became clear which patients these were.

\section{Factors Influencing Incidence of Late Epilepsy}

It is immediately striking that the incidence of late epilepsy in those who had an early fit $(28.5 \%)$ was four times as great as in those who did not, although at least half of the latter had serious injuries. By contrast the lowest incidence was in the mild, uncomplicated injuries (post-traumatic amnesia less than one hour, no depressed fracture, and no haematoma) without early epilepsy, only one of 100 such cases followed developing a late fit.

When, however, patients with mild injuries who had had an early fit were followed up a number proved to have late epilepsy as well, so that the overall incidence of late epilepsy in uncomplicated mild injuries was $4.5 \%$. An analysis of this group revealed it to be composed entirely of children under the age of 8 years. All four children with a mild injury and an early fit had subsequent epilepsy, but none of the four patients over the age of 14 with this history had later epilepsy. Nor did the four adults with post-traumatic amnesia up to 24 hours and an early fit but an uncomplicated injury have late epilepsy. Furthermore, the one case of late epilepsy in the 100 mild injuries was a child of 11 . There was not a single instance of late epilepsy in an adult (over 14 years) with less than 24 hours' post-traumatic amnesia even when there had been early epilepsy, unless there was either a depressed fracture or an intracranial haematoma. Even when cases with these complications were included, and the total number of patients with less than an hour's post-traumatic amnesia (whether or not they had an early fit) was considered, this influence of age was apparent. For $10 \%$ of the 70 children under 14 had late fits, compared with only $3.9 \%$ of 76 patients over 14 years.

When more serious injuries are considered the interdependence of various factors makes analysis in terms of causal relationships very difficult. For example, penetrating depressed fractures and acute subdural haematomas tend to be associated with prolonged post-traumatic amnesia. In any one
TABle VI

POST-TRAUMATIC AMNESIA AND LATE EPILEPSY (Cases with early fits included)

\begin{tabular}{c|cc|c|c|c|c}
\hline $\begin{array}{c}\text { Post- } \\
\text { traumatic } \\
\text { Amnesia }\end{array}$ & $\begin{array}{c}\text { Total } \\
\text { Late } \\
\text { Epilepsy }\end{array}$ & $\begin{array}{c}\text { With } \\
\text { Intracranial } \\
\text { Haematoma }\end{array}$ & $\begin{array}{c}\text { With } \\
\text { Depressed } \\
\text { Fracture } \\
\dagger\end{array}$ & $\begin{array}{c}\text { Without } \\
\text { Haematoma } \\
\text { or } \\
\text { Depressed } \\
\text { Fracture }\end{array}$ \\
\hline $\begin{array}{c}\text { Less than } \\
24 \text { hours }\end{array}$ & $\frac{11}{161}$ & $(6.7 \%)$ & $\frac{3}{15}(20 \%)$ & $\frac{3}{36}$ & $(8.3 \%)$ & $\frac{5}{110}(4 \cdot 5 \%)$ \\
$\begin{array}{c}\text { More than } \\
24 \text { hours }\end{array}$ & $\frac{16}{113}(14.2 \%)$ & $\frac{7}{20}(35 \%)$ & $\frac{7}{15}$ & $(46.6 \%)$ & $\frac{3}{88}$ & $(3.4 \%)$ \\
\hline Total & $\frac{28}{275}$ & $(9.8 \%)$ & $\frac{10}{35}(28.5 \%)$ & $\frac{11}{52}$ & $(21 \cdot 2 \%)$ & $\frac{8}{198}(4 \cdot 1 \%)$ \\
\hline
\end{tabular}

*One patient had haematoma and depressed fracture and appears in both columns.

tOne patient with depressed fracture had unknown post-traumatic amnesia and appears only in totals.

patient the prognosis must take all relevant factors into account. Nonetheless, certain connexions between the incidence of late epilepsy and these factors can be discerned.

The initial impression that a long period of posttraumatic amnesia (more than 24 hours) contributed to a high incidence of late epilepsy $(14.2 \%$ compared with $6.7 \%$ in less severe injuries) is a partial truth. For it was only when associated with a depressed fracture or intracranial haematoma that a strikingly high incidence was recorded $(46.6 \%$ and $35 \%$ ). Indeed in the 88 cases with a long period of post-traumatic amnesia but neither of these complications, the incidence was only $3.4 \%$. Similarly depressed fracture of itself proved to have less influence alone than the overall figures for late epilepsy $(21.2 \%)$ suggest. It was only when accompanied by a long period of post-traumatic amnesia that a really high rate of late fits occurred $(46.6 \%)$. As might have been anticipated penetration of the dura carried a high risk of fits. Of 44 patients with depressed fracture and without early epilepsy who were followed, 26 had non-penetrating injuries and two developed late epilepsy $(7 \cdot 7 \%)$ whereas 18 had penetrating injuries and five developed epilepsy (28\%).

Intracranial haematoma was followed by late epilepsy in $28.5 \%$ of cases followed and this increased incidence was much less related to the duration of the post-traumatic amnesia than in the case of depressed fracture. The figures for long and short periods of post-traumatic amnesia were $35 \%$ and $20 \%$ respectively. Of the 35 survivors after intracranial haematoma followed, six $(17 \%)$ had late fits, not having had them during the acute period, and altogether a third of them had fits at some stage. This high incidence might be anticipated with acute subdural and intracerebral haematoma 
but an incidence of $25 \%$ with extradural haematoma alone should be noted. Of the 25 patients with subarachnoid haemorrhage who were followed five had late fits.

\section{Onset and Type of Late Epilepsy}

Generalized attacks were more common than focal (10 to six) and one case of undoubted temporal lobe epilepsy occurred. Of the 28 patients with late epilepsy, nine had several fits. Of the remainder, seven had only a single fit and the others two or three, and all of these were followed for seven years after the first fit. It seems, therefore, that the epilepsy does not tend to be severe. The persistent cases were among those whose first fit occurred within a year of injury.

The time of onset of the epilepsy varied. By the end of the first year after the injury $50 \%$ of the late epileptics had had their first fit, and $70 \%$ by the end of the second year. There were sporadic cases developing up to seven years. One case occurred between the eighteenth and twenty-fourth months, the "negative period" of Phillips (1954), who found no cases developing at this time. The same range was found among the eight cases of late epilepsy where there had also been early attacks, as in those who had only late fits.

\section{Role of Anticonvulsants}

Such limited observation as we have been able to make suggests that phenobarbitone may be an effective prophylactic against late epilepsy. We have accurate information about not only the anticonvulsants prescribed for but that actually taken by 36 patients. This is a small but significant group consisting of a number of those who had early fits and were followed up, and also some who had late fits only, that is to say, a group with a proven epileptic predisposition. Of $\mathbf{2 4}$ who took drugs for six months or more, nine had one or more late fits. In six of these patients the first fit occurred as soon as the drug was withdrawn or temporarily omitted. Only one patient had a fit while taking phenobarbitone. Of 12 patients who had no anticonvulsants, six developed late epilepsy. The incidence of complications and severe injuries was approximately equal in the groups with and without drugs.

It seems that those patients where this study has shown to be predisposed to late epilepsy should be given anticonvulsants for a period of two years or so, which covers the period of onset of most cases. It is of interest to reflect that the time of onset of late epilepsy, and the speculations in regard to patho- genesis which are based on this, may be spurious. It may be determined not only by the development of a particular pathological stage of the recovering brain but simply by the chance of discontinuing the drugs.

\section{CONCLUSIONS}

It seems likely that the wide range of varying reports on the incidence of epilepsy after closed head injuries derives from the selection of cases. The incidence of early fits in this unselected series of 821 direct admissions was $3.9 \%$. This figure, however, is of limited value when discussing the prognosis of any one patient. The risk of late epilepsy, for example, was considerable in those who had had early epilepsy, $28.5 \%$. This was four times greater than the incidence of late epilepsy without early attacks and clearly a fit in the acute stage cannot be ignored in prognosis. On the other hand, it was encouraging to find that early and late fits after trivial injuries were confined to children; and also that no adult with a mild cerebral concussion with less than 24 hours' post-traumatic amnesia and without a depressed fracture or intracraniab haemorrhage developed late epilepsy, even if there had been early fits.

Early epilepsy was more frequent in cases witk more than 24 hours' post-traumatic amnesia, witk depressed fracture and with intracranial haematoma each of these factors alone appreciably increased the incidence. In the cases with intracranial haematomas fits accompanied other signs of cerebral compres? sion. They were rarely the initial, and never the only, sign of such a complication.

The influence of these three factors on late epilepsy was a little different. Intracranial haematoma was the only factor which alone had a much greater incidence of late epilepsy than the group as a whole; nearly a third of the survivors had a late fit. Neither prolonged amnesia nor depressed fracture alone carried a very serious risk of epilepsy, but the two together made for the highest rate of late epilepsy of all the groups studied $(46.6 \%)$. The striking differences between the incidence of epilepsy after penetrating missile wounds (nearly $50 \%$ ) and the low incidence among closed head injuries (3-6\%) has been noted many times before. This discrepancy, however, may be apparent only. Depressed fractures with a long period of post-traumatic amnesia or an intracranial clot with local compression are comparable in their local intensity of injury to penetrating missile wounds and it is interesting that the incidence of epilepsy in these groups should be comparable to the missile wounds series. This fact is lost in any large series of closed head injuries when 
diluted with many cases of uncomplicated concussion.

Phillips (1954) studied the time of onset of epilepsy and divided the onset of traumatic epilepsy into a primary phase within the first three months due to the immediate effects of the injury; a reactionary phase from three to 18 months in which the appearance of fits may be related to the recovery of damaged cells; and a secondary phase where fits appearing for the first time more than two years after the injury may be associated with cerebral scars. The present series lends support to this division and indeed sharpens the distinction of the primary phase. For in this series all but one case of early epilepsy developed within the first week. In severe head injuries we have noted frequently that the beginning of clinical improvement in a patient some weeks after injury may be accompanied by the appearance of a fit, as if reintegration were taking place. Moreover, the appearance of epilepsy in a few cases years after the injury makes a different explanation, such as cortical scarring, rather than "integration" a likely one. Certainly the remarkable lag phase during the first three months when no fits begin calls for an explanation.

\section{SUMMARY}

Observations on early and late traumatic epilepsy based on 1,000 consecutive cases of head injury not due to missiles are made.

Some factors associated with early fits are analysed and the significance of the epilepsy is discussed.

Our thanks are due to Mr. J. C. Scott, Director of the Accident Service, Radcliffe Infirmary, where these patients were admitted, and to Miss Sheila Nicholson for her invaluable help in the follow-up of these patients.

\section{REFERENCES}

Ascroft, P. B. (1941). Brit. med. J., 1, 739.

Feinberg, P. (1934). Epilepsie und Trauma. Oberholzer, Zürich

Garland, H. G. (1942). Proc. roy. Soc. Med., 35, 773.

Gurdjian, E. S., and Webster, J. E. (1958). Head Injuries. J. and A. Churchill, London.

Lewin, W. (1953). Brit. med. J., 1, 1239.

Penfield, W., and Jasper, H. (1954). Epilepsy and the Functional Anatomy of the Human Brain. Little, Brown, Boston. and Shaver, M. (1945). Res. Publ. Ass. nerv. ment. Dis., 24,620 .

Phillips, G. (1954). J. Neurol., Neurosurg. Psychiat., 17, 1.

Rowbotham, G. F. (1942). Acute Injuries of the Head, Livingstone, Edinburgh.

Russell, W. R. (1932). Proc. roy. Soc. Med., 25, 751.

-, and Whitty, C. W. M. (1952). J. Neurol., Neurosurg. Psychiat., $15,93$.

Symonds, C. P. (1935). Lancet, 2, 1217.

Wagstaffe, W. W. (1928). Lancet, $2,861$.

Walton, J. N. (1956). Subarachnoid Haemorrhage. Livingstone, Edinburgh and London. 